\title{
Modular, Lightweight, Wireless Potentiostat-on-a-Disc for Electrochemical Detection in Centrifugal Microfluidics
}

Thoppe Rajendran, Sriram; Scarano, Ermes; Bergkamp, Max H.; Capria, Alessandro M.; Cheng, ChungHsiang; Sanger, Kuldeep; Ferrari, Giorgio; Nielsen, Line Hagner; Hwu, En Te; Zor, Kinga

Total number of authors:

11

Published in:

Analytical Chemistry

Link to article, DOI:

10.1021/acs.analchem.9b02026

Publication date:

2019

Document Version

Peer reviewed version

Link back to DTU Orbit

Citation (APA):

Thoppe Rajendran, S., Scarano, E., Bergkamp, M. H., Capria, A. M., Cheng, C-H., Sanger, K., Ferrari, G.,

Nielsen, L. H., Hwu, E. T., Zor, K., \& Boisen, A. (2019). Modular, Lightweight, Wireless Potentiostat-on-a-Disc for Electrochemical Detection in Centrifugal Microfluidics. Analytical Chemistry, 91, 11620-11628.

https://doi.org/10.1021/acs.analchem.9b02026

\section{General rights}

Copyright and moral rights for the publications made accessible in the public portal are retained by the authors and/or other copyright owners and it is a condition of accessing publications that users recognise and abide by the legal requirements associated with these rights.

- Users may download and print one copy of any publication from the public portal for the purpose of private study or research.

- You may not further distribute the material or use it for any profit-making activity or commercial gain

- You may freely distribute the URL identifying the publication in the public portal 
Article

Subscriber access provided by DTU Library

\section{Modular, lightweight, wireless potentiostat-on-a-disc (PoD) for elec-trochemical detection in centrifugal microfluidics}

Sriram Thoppe Rajendran, Ermes Scarano, Max H Bergkamp, Alessandro M Capria, Chung-Hsiang Cheng, Kuldeep Sanger, Giorgio Ferrari, Line H Nielsen, En-Te Hwu, Kinga Zór, and Anja Boisen

Anal. Chem., Just Accepted Manuscript • DOI: 10.1021/acs.analchem.9b02026 • Publication Date (Web): 23 Jul 2019

Downloaded from pubs.acs.org on August 5, 2019

\section{Just Accepted}

"Just Accepted" manuscripts have been peer-reviewed and accepted for publication. They are posted online prior to technical editing, formatting for publication and author proofing. The American Chemical Society provides "Just Accepted" as a service to the research community to expedite the dissemination of scientific material as soon as possible after acceptance. "Just Accepted" manuscripts appear in full in PDF format accompanied by an HTML abstract. "Just Accepted" manuscripts have been fully peer reviewed, but should not be considered the official version of record. They are citable by the Digital Object Identifier (DOI®). "Just Accepted" is an optional service offered to authors. Therefore, the "Just Accepted" Web site may not include all articles that will be published in the journal. After a manuscript is technically edited and formatted, it will be removed from the "Just Accepted" Web site and published as an ASAP article. Note that technical editing may introduce minor changes to the manuscript text and/or graphics which could affect content, and all legal disclaimers and ethical guidelines that apply to the journal pertain. ACS cannot be held responsible for errors or consequences arising from the use of information contained in these "Just Accepted" manuscripts. 


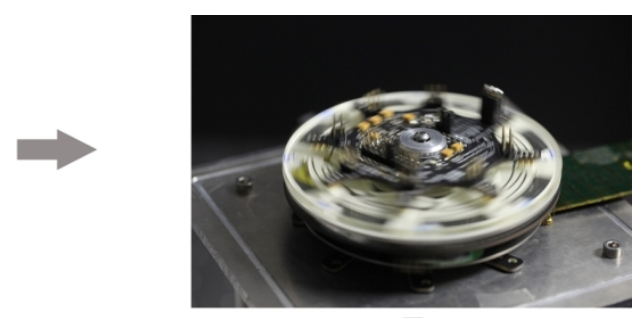

Lab-on-a-disc

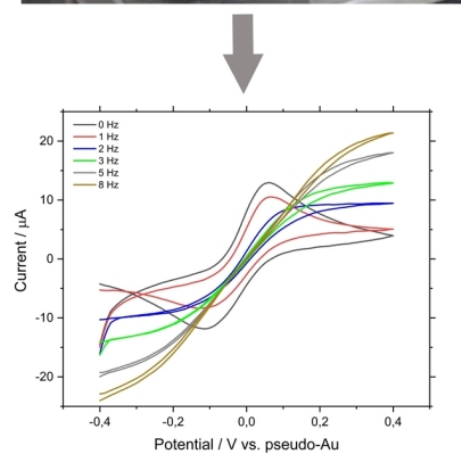

Abstract figure

$76 \times 43 \mathrm{~mm}(600 \times 600 \mathrm{DPI})$ 

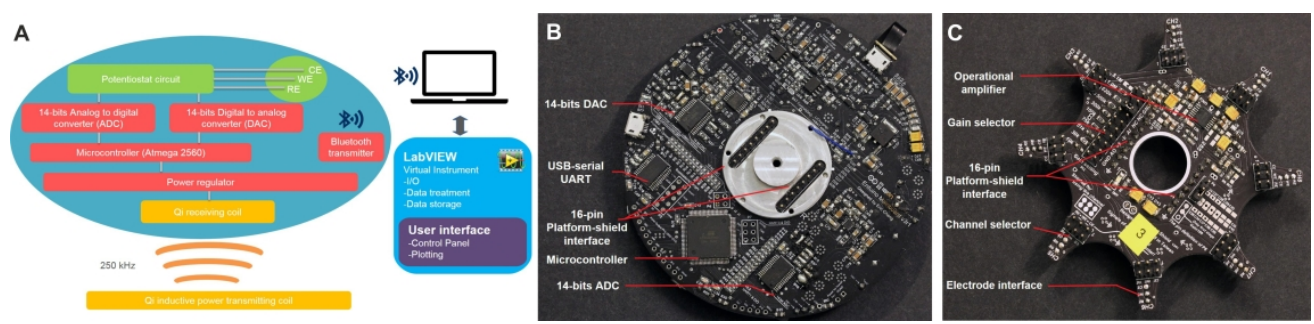

Figure 1. A) A simplified block diagram of the PoD unit; B) photographs of the main circuits of the PoD, the core circuit (platform) and shield (C) with indication of the electronic components.

$211 \times 50 \mathrm{~mm}(600 \times 600 \mathrm{DPI})$ 


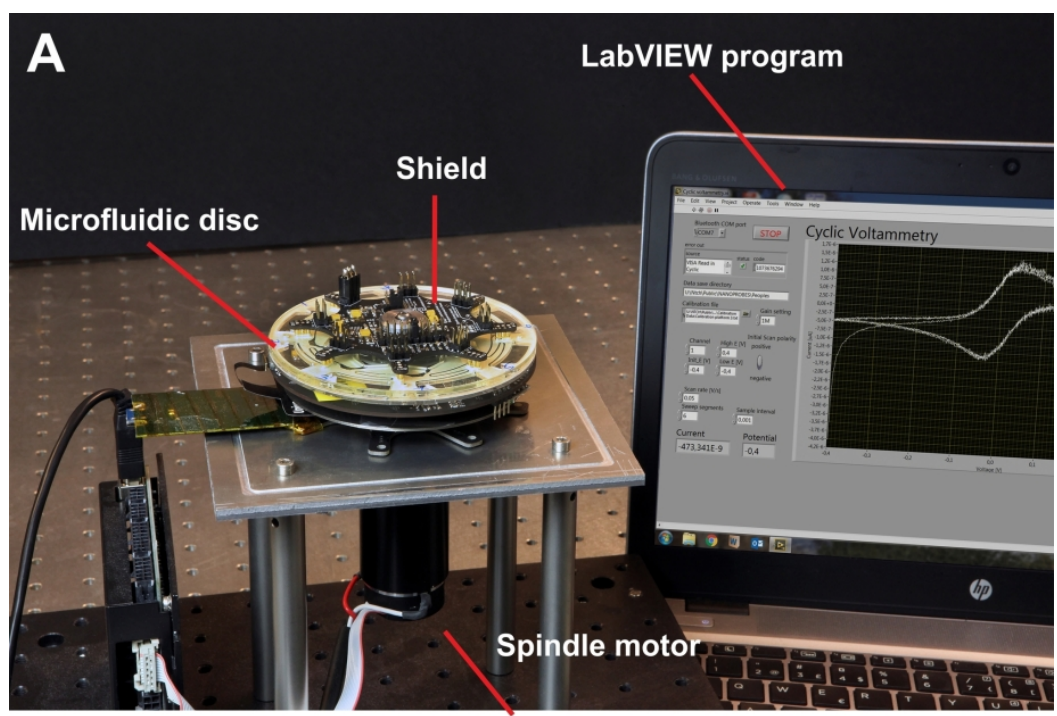

B

Fastening screw

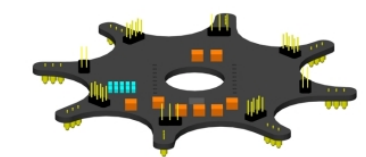

Shield

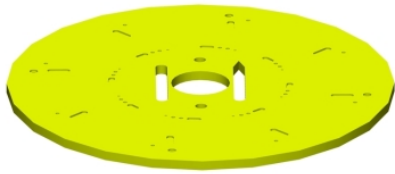

Microfluidic disc

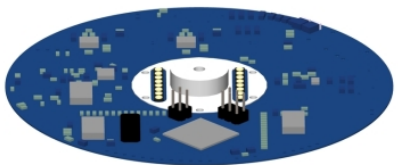

Platfrom with disc holder

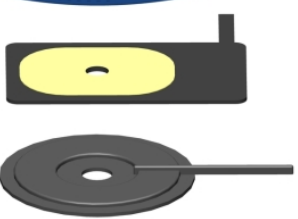

Power receiver

Power coil

Figure 2. (A) Experimental setup with spindle motor, microfluidic disc assembled with the F-on-a-disc (PoD) and control software interface; (B) Exploded view of the assembled PoD with the LoD device.

$$
84 \times 126 \mathrm{~mm}(600 \times 600 \text { DPI })
$$



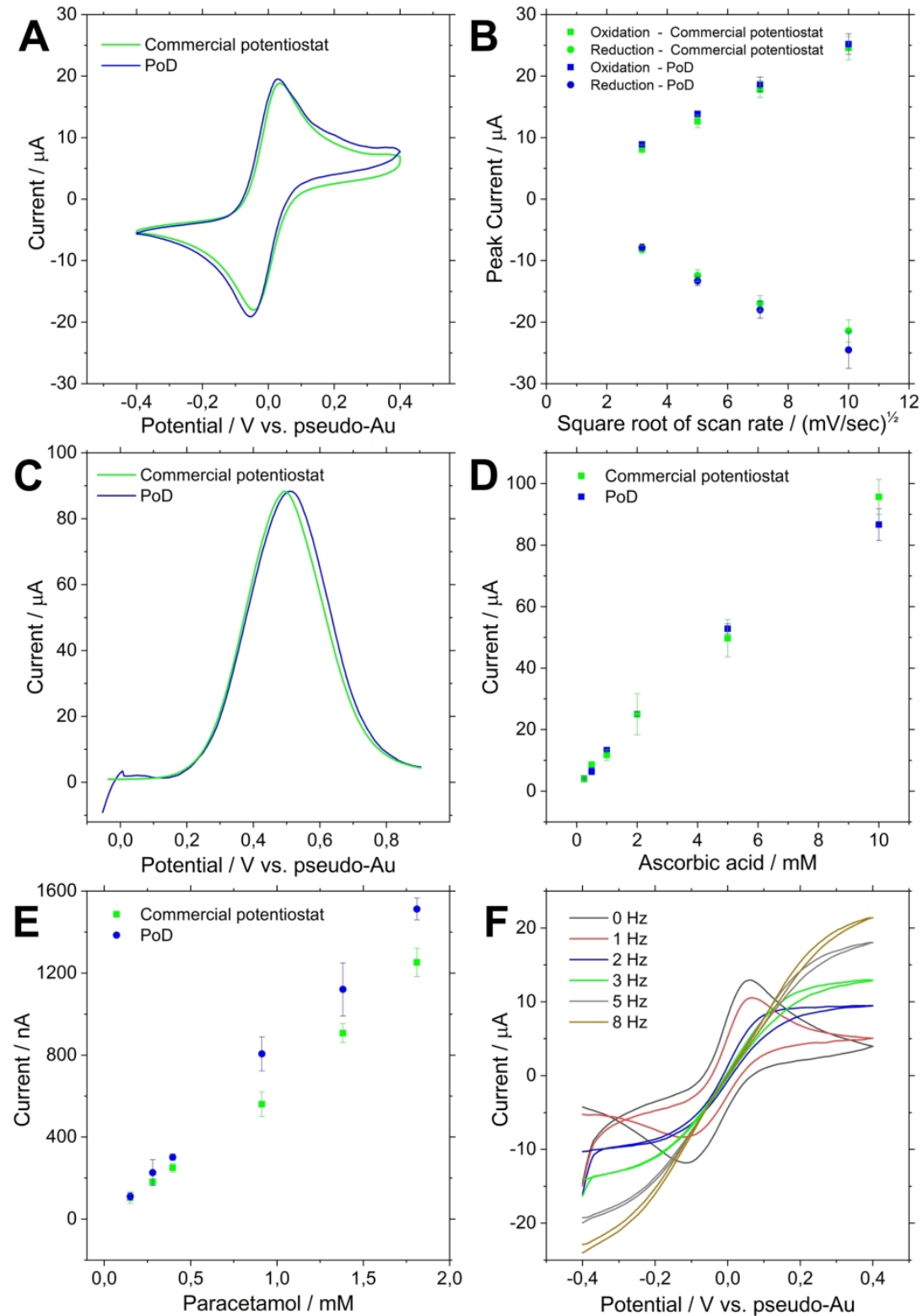

Figure 3. (A) Representative CVs of $1 \mathrm{mM}$ FiC with PoD and commercial potentiostat, Au WE area: $50 \mathrm{~mm}$, applied potential vs. pseudo Au-RE, Au-CE. The CVs were performed at a scan rate of $50 \mathrm{mV} / \mathrm{sec}$; (B)

Oxidation and reduction peak currents as a function of the square root of the scan rate; (C) SWVs of $10 \mathrm{mM}$ ascorbic acid, (Carbon WE area: $50 \mathrm{~mm} 2$, applied potential vs. Ag-RE, carbon CE). The SWVs were recorded with a potential step $0.004 \mathrm{~V}$, frequency $10 \mathrm{~Hz}$, amplitude $0.025 \mathrm{~V}$; (D) Calibration plot recorded for different concentrations of ascorbic acid; (E) Calibration curve of paracetamol obtained with PoD and commercial potentiostat, using Au WE (area: $50 \mathrm{~mm} 2$ ), Au-CE and Au-RE. Applied potential $+0.4 \mathrm{~V}$ vs. pseudo Au-RE; (F) CVs were recorded at various rotation speeds at $100 \mathrm{mV} / \mathrm{sec}$ scan rate in $1 \mathrm{mM} \mathrm{FiC,} \mathrm{Au}$ WE area: $0.69 \mathrm{~mm} 2$, applied potential vs. pseudo Au-RE, Au-CE. All measurements were performed in PBS as supporting electrolyte, $\mathrm{pH} 7.4$ and standard deviation were calculated based on triplicates $(n=3)$.

\section{$83 \times 120 \mathrm{~mm}(600 \times 600 \mathrm{DPI})$}




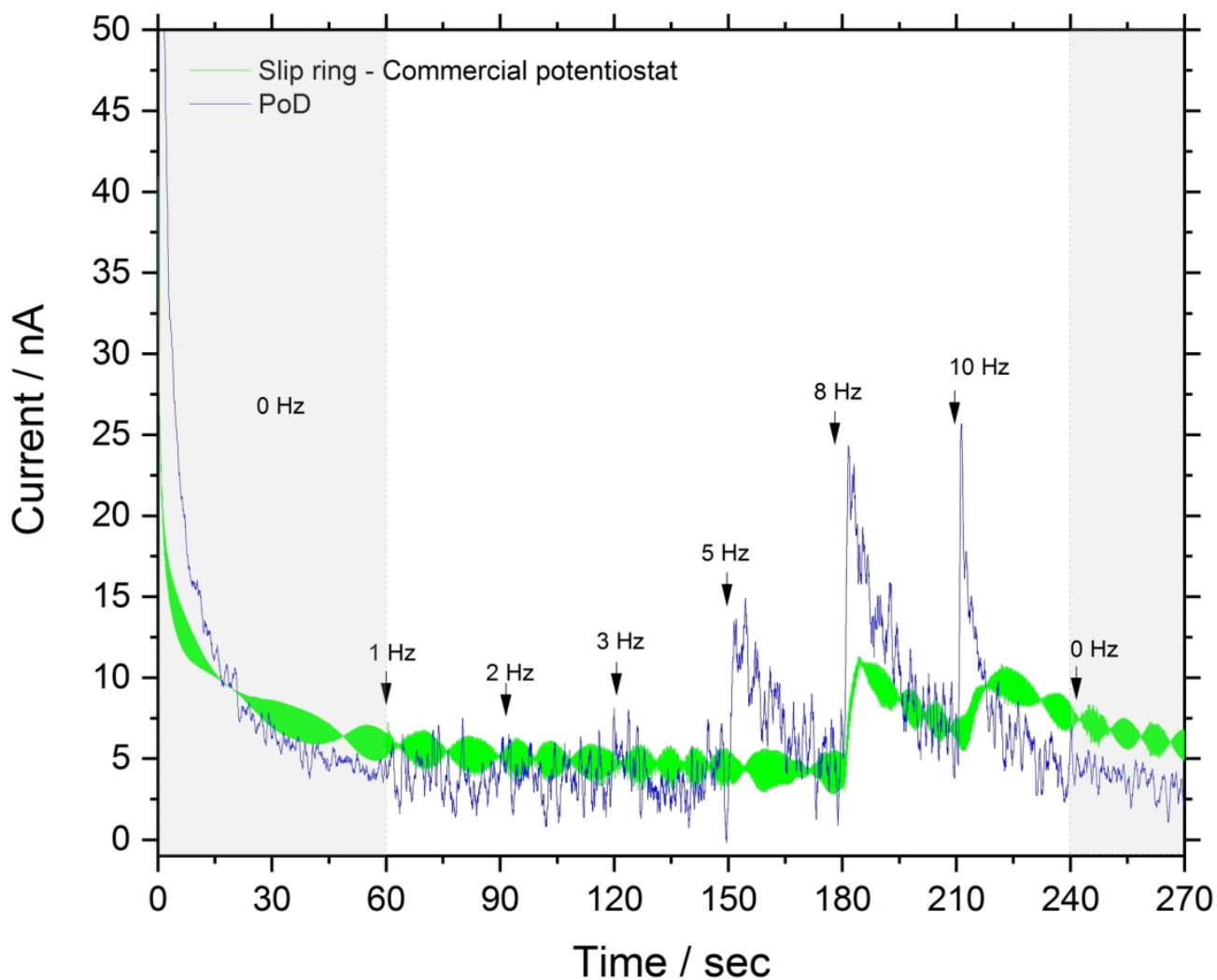

Figure 4. Baseline noise measured during rotation in fluidics using PBS at applied potential of $+0.4 \mathrm{~V}$ vs. pseudo-Au-RE recorded with PoD and commercial potentiostat using the Au electrodes (WE area: $0.69 \mathrm{~mm}$, pseudo-Au-RE, Au CE) pat-terned on PMMA.

\section{$85 \times 68 \mathrm{~mm}(600 \times 600 \mathrm{DPI})$}



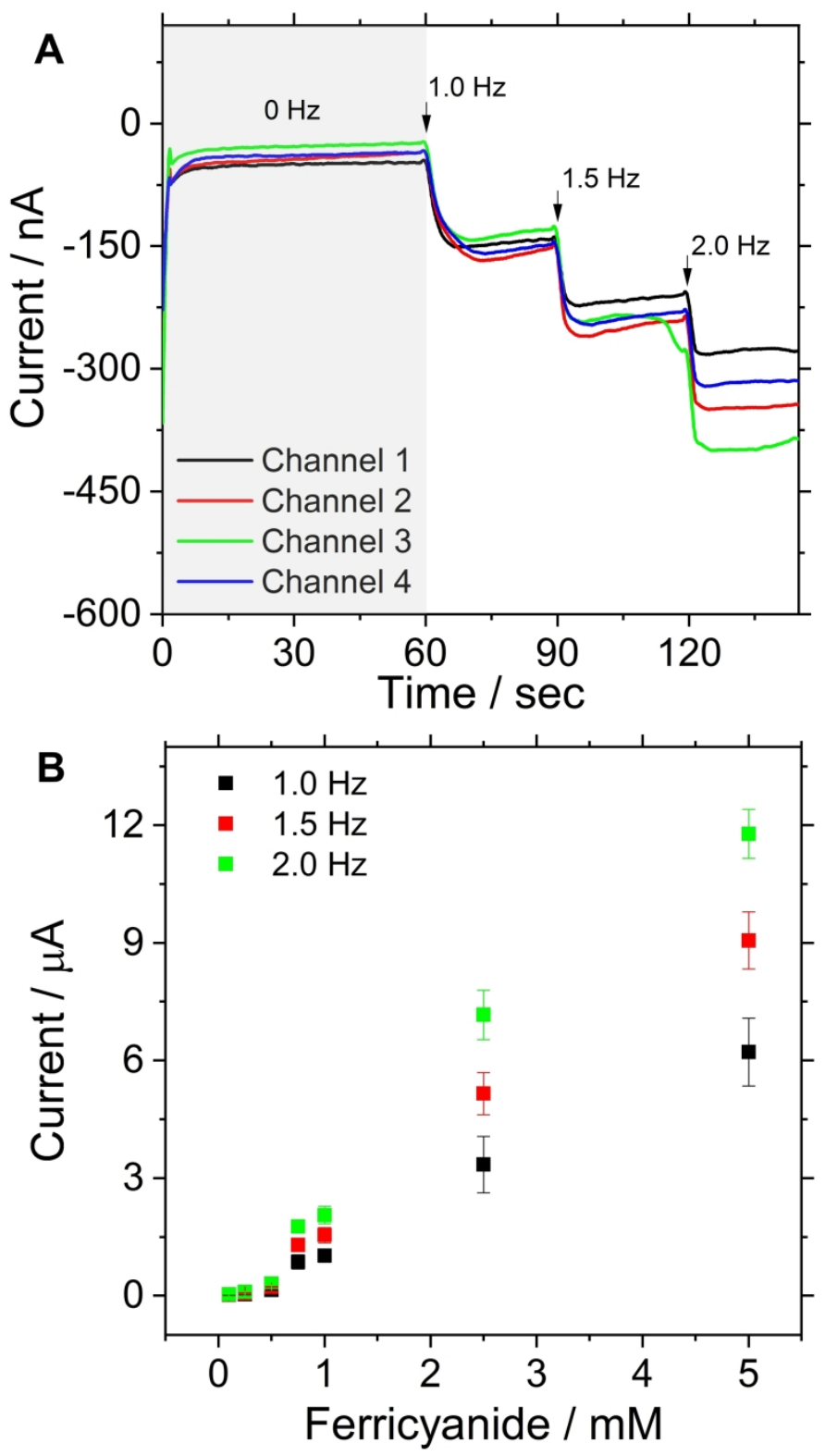

Figure 5. (A) Multichannel amperometric measurement in the LoD platform of $500 \mu \mathrm{M} \mathrm{FiC} \mathrm{in} \mathrm{PBS,} \mathrm{pH} 7.4$ as supporting electrolyte at an applied potential of $-0.4 \mathrm{~V}$ vs. pseudo-Au RE, using on PMMA patterned $A u$ electrodes (WE area: $0.69 \mathrm{~mm} 2$, pseudo Au-RE, Au CE) under 1, 1.5 and $2 \mathrm{~Hz}$; (B). Calibration plot, showing the normalized current changes, recorded for different concentrations of FiC during rotation at 1 , 1.5 and $2 \mathrm{~Hz},(n=3)$.

$84 \times 148 \mathrm{~mm}(600 \times 600 \mathrm{DPI})$ 
A

1

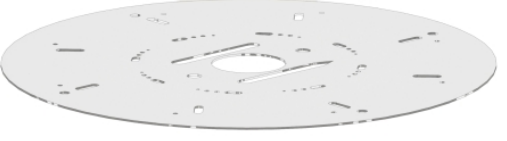

2

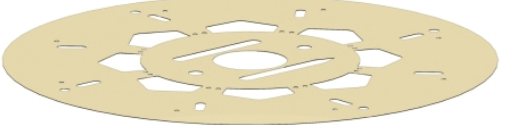

3

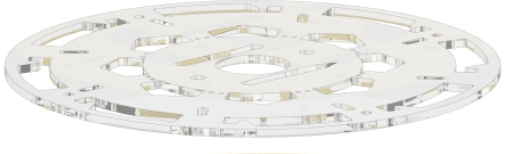

4

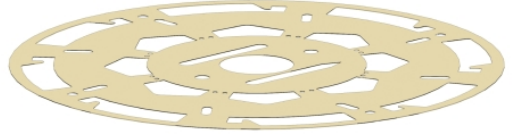

5

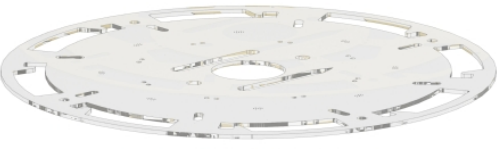

6

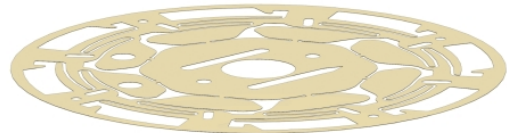

7

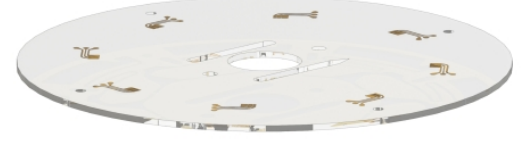

C
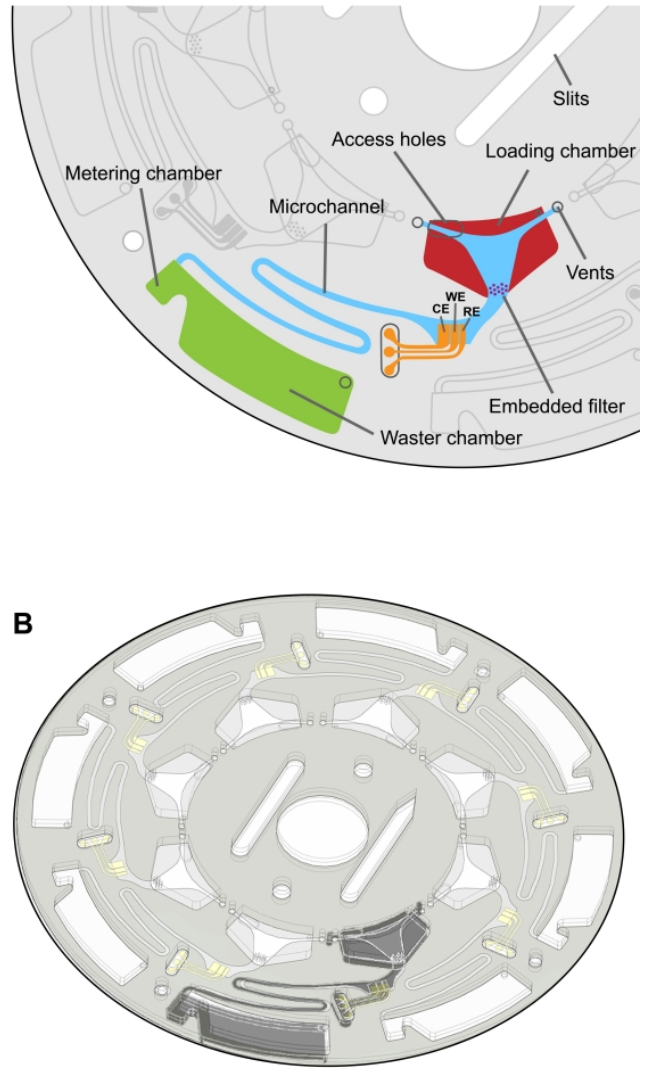

Figure 6. (A) Exploded view of the microfluidic disc; (B) View of the assembled microfluidic disc, with a highlighted measurement unit; (C) A cartoon showing one measurement unit with its func-tional parts $508 \times 440 \mathrm{~mm}(300 \times 300 \mathrm{DPI})$ 

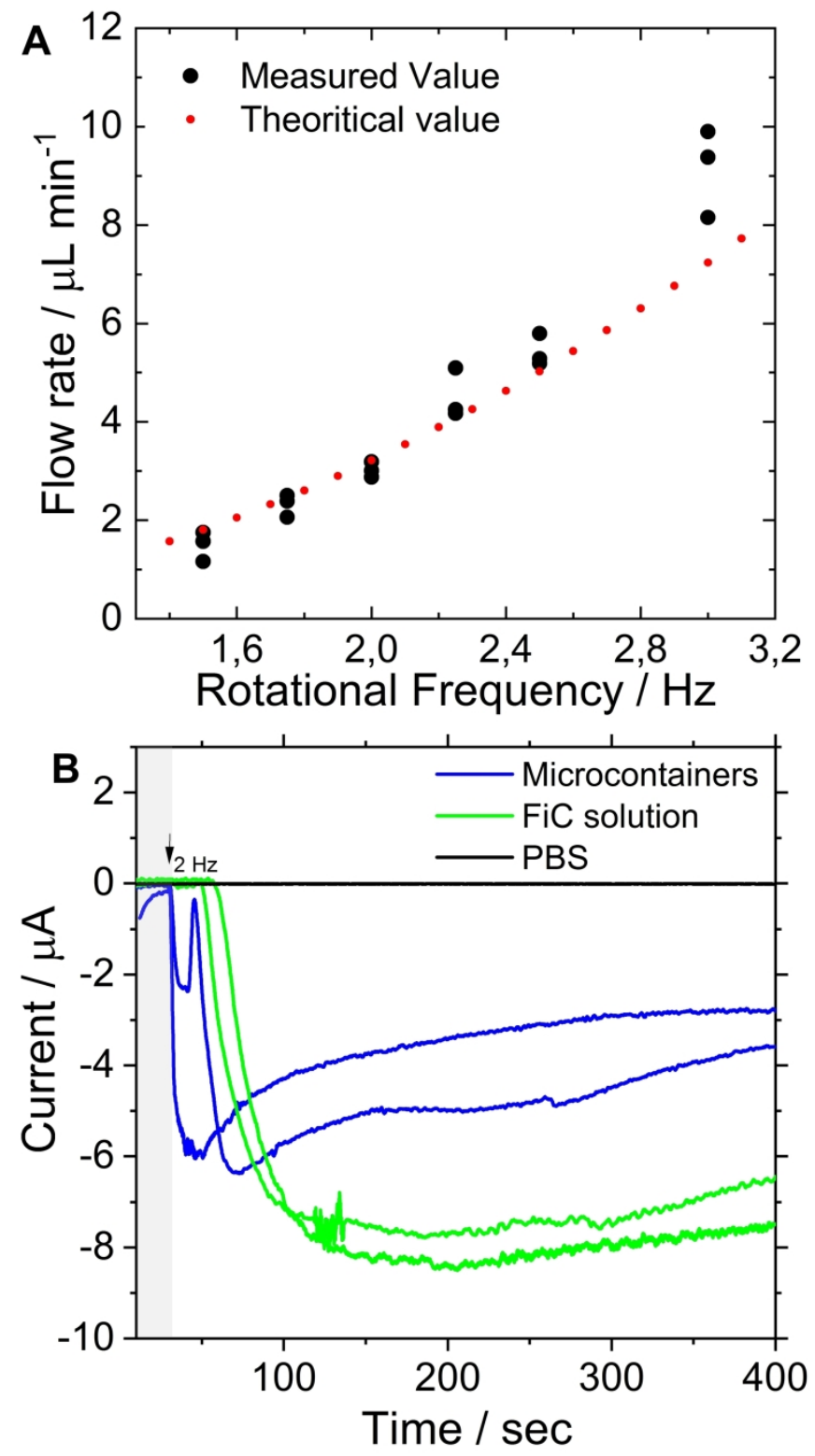

Figure 7. (A) Optical measurements of flow rate vs. rotation frequency $(n=3)$, for LoD platforms with microchannels in $86 \mu \mathrm{m}$ thick PSA; (B) Amperometric release and dissolution of FiC in PBS, pH 7.4 as supporting electrolyte, at a potential of $+0.4 \mathrm{~V}$ vs. Au pseudo-RE. PMMA patterned fabricated gold Au electrodes (WE area: $0.69 \mathrm{~mm} 2$, pseudo Au-RE, Au CE).

$$
84 \times 152 \mathrm{~mm}(600 \times 600 \mathrm{DPI})
$$


ABSTRACT: Interfacing electrochemical sensors in lab-on-a-disc (LoD) system with a potentiostat is often tedious and challenging./ We here present the first multichannel, modular, lightweight and wirelessly powered, custom-built potentiostat-on-a-disc (PoD) for centrifugal microfluidic applications. The developed potentiostat is in the form factor of a typical DVD and weighs only $127 \mathrm{~g}$. The design of the potentiostat facilitates easy and robust interfacing with the electrodes in the LoD system, while enabling real-time electrochemical detection during rotation. The device can perform different electroanalytical techniques such as cyclic voltammetry, square wave voltammetry, amperometry while being controlled by custom-made software. Measurements were conducted with and without rotation using both in-

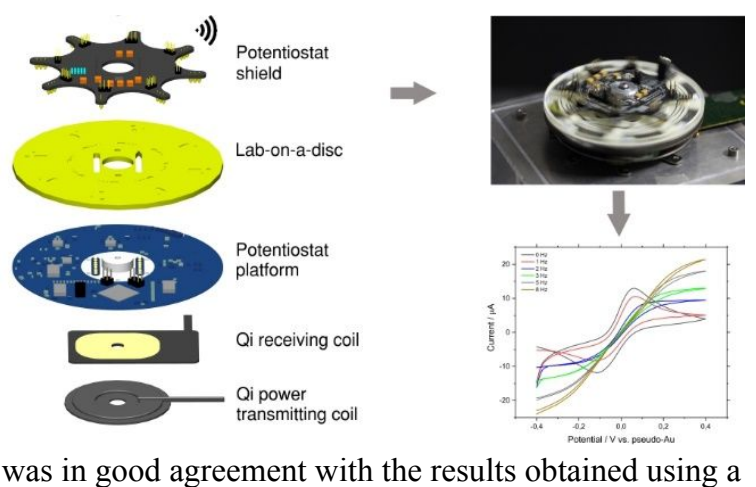
house fabricated and commercial electrodes. The performance of the PoD was in good agreement with the results obtained using a commercial potentiostat with a measured current resolution of $200 \mathrm{pA}$. As a proof-of-concept, we performed a real-time release study of an electrochemically active compound from microdevices used for drug delivery.

Electrochemical (bio) sensors ${ }^{1,2}$ have been successfully used in biomedical application ${ }^{3}$, for food analysis ${ }^{4,5}$, environmental monitoring ${ }^{6}$ as well as for drug development ${ }^{7,8}$. These sensors have been proposed suitable for integration in microfluidics 9,10 and were used in point of care devices ${ }^{11}$, cell-based assays ${ }^{8}$ and in combination with wireless data transmission 12,13. The electrochemical transducer (electrode) and instrumentation (potentiostat) can be miniaturized without losing performance 10,14-16 at a relatively low cost with a minimal power demand ${ }^{17-19}$. Therefore, electrochemical detection proved to be suitable for integration with microfluidics when developing portable, affordable devices for point of care, point of need or on-site analysis.

Centrifugal microfluidic platforms or so-called lab-on-a-disc (LoD) systems gained interest in both academic research and industry ${ }^{20-25}$. These microfluidic devices require relatively simple instrumentation for liquid handling, i.e., a spinning motor. The miniaturization and automation of the motor facilitates a simple, compact and inexpensive system enabling the execution of complicated liquid handling steps ${ }^{24,26}$ on a small footprint such as a compact disc. LoD devices are mainly used in combination with contact-free optical detection 27-32. Typically, in the case of optical sensing, the transducer is not in direct contact with the detector. Therefore, the measurement could be easily performed by the addition of a peripheral optical device. However, the spinning of the disc should be stopped for optical measurements. Measurements during rotation are particularly challenging when there is a need for direct contact between transducer and detector. There are several examples describing the integration of electrochemical ${ }^{31,33-37}$ detection in LoD devices. In certain cases, the measurements are performed in static condition, at end-point after fluidic operations were carried out $34,37,38$ or during rotation with the help of a slip ring, 31,33,35,37,39 which was in turn connected to a commercial potentiostat. 
Nevertheless, both methods create complications in handling and necessitate more time for a measurement. Although a slip ring enables real-time measurements, it adds additional complexity to the experimental setup and severely limits the number of possible electrical contacts. Moreover, the brush connector in the slip ring wears out with time and hence, limits rotational frequency of LoD devices ${ }^{40}$.

We have previously used mercury based slip rings, which has lower resistance in comparison to the typical slip rings with brush connectors ${ }^{35}$, however even for single channel measurements, the interfacing with a commercial potentiostat was rather bulky and complex ${ }^{35,37}$. In certain applications, e.g. immunoassays, end point measurements are suitable and there is no need for real-time detection. However, when the detection needs to be carried out on-site or a reaction must be followed in real-time, there is a need for a platform, which can be portable, enables straightforward interfacing and reliable detection during rotation. There are several application of the LoD devices, for point of care applications ${ }^{20,41-43}$ on-site ${ }^{44,45}$, at-line $28,37,46$ and in-line ${ }^{47}$ monitoring. However, portable electrochemical analyzers used in combination with LoD systems, which enable real-time, detection during rotation are scarce.

In the last few years there have been major developments in creating a compact, modular, portable centrifugal platform with integrated power generation and wireless communication system 40,48-51. The electrified-Lab-on-a-Disc (eLoaD) ${ }^{49}$ offers various detection possibilities ${ }^{[51]}$ as well as temperature and valve control 50. More recently, a portable battery powered commercial potentiostat was integrated on the disc for real-time measurements ${ }^{52}$. This approach is a step closer in solving the interfacing challenge. Although, it eliminates the need for slip rings, it still suffers from the trivial problem of having a reliable electrical interface between the electrode and the potentiostat. As it has been highlighted by Bauer et al. ${ }^{52}$, due to poor contacts, significant noise can be generated during spinning, thus requiring fast Fourier transform data treatment. Moreover, the weight of the placed device affects inertia during spin, particularly when there is a need for quick acceleration and deceleration. In addition, the complex casing around the disc prohibits the view of the channels during spin.

This further emphasizes the need for a solution for improved interfacing of potentiostats with LoD devices.

Despite the development in this area, to our knowledge, there are no reports of a custom-designed potentiostat for LoD devices, which enables accurate electrochemical detection during rotation. Here, we present the development and performance of a wirelessly powered potentiostat integrated with LoD system with embedded electrodes. The performance of the potentiostat-on-a- disc (PoD) has been compared with a commercial potentiostat and we

carried out a proof-of-concept study, evaluating release from drug delivery microdevices.

\section{EXPERIMENTAL SECTION}

Fabrication of PoD. The disc shaped platform and the PoD shield circuits were designed with a computer aided design (CAD) software Altium (Altium LLC, La Jolla, USA). The platform is controlled by an ATmega2560 microcontroller, which integrates a $205 \mathrm{kHz}$ inductive wireless power receiver, a low noise power regulator, single channel 14-bit digital-to-analog converter (DAC)/ analog-to-digital-converter (ADC), two input/output pin headers and a $2.4 \mathrm{GHz}$ Bluetooth wireless communication module. The microcontroller firmware was programmed with an Arduino (Arduino, Turin, Italy) integrated development environment. All the electronic components were purchased from RS components (RS Components, Corby, UK) and Digi-key (DigiKey Electronics, Minnesota, USA). In addition the multichannel shield composed of four potentiostat circuits, each of them in the three operational amplifier buffered reference configuration driven by the same input potential, and a digitally controlled analog switch for output multiplexing. The printed circuit boards (PCBs) were from ShingTech, Taiwan. The components were assembled and tested in-house.

Fabrication of LoD. The centrifugal microfluidics device with eight detection units, consisting of gold ( $\mathrm{Au}$ ) electrode arrays (working electrode (WE), counter electrode (CE) and pseudoreference electrode (pseudo-RE)). The electrodes patterned on the bottom of the poly(methyl methacrylate (PMMA) substrate were fabricated as described earlier ${ }^{37,53,54}$, using e-beam evaporation $(20 \mathrm{~nm} \mathrm{Cr}$ adhesion layer / $200 \mathrm{~nm} \mathrm{Au}$ ). The LoD device was designed using software Solidworks 2017 (Dassault Systèmes, Vélizy-Villacoublay, France). The optical grade PMMA (Evonik Industries AG, Essen, Germany) was cut using a computercontrolled Epilog Mini 18 laser cutter equipped with a $30 \mathrm{~W} \mathrm{CO}_{2}$ laser (Epilog Laser, Houten, The Nederland). One PMMA layer has been designed to have pores of $160 \mu \mathrm{M} \varnothing$, with $0.5 \mathrm{~mm}$ spacing, to act as filters to physically prevent the microcontainers from blocking the channels connecting the loading to the detection chamber. Two different double-sided pressure sensitive adhesive (PSA) tapes each of $140 \mu \mathrm{M}$ thickness (ARcare 90106, Adhesive Research, Limerick, Ireland) and $84 \mu \mathrm{M}$ thickness (ARcare 7840, Adhesive Research, Limerick, Ireland) were cut using a precision blade cutter (CE-40, Graphtech, USA). The PMMA layers of the LoD system were bonded together via the 
PSA and placed in the hydraulic bonding press (PW20, Paul-Otto Weber GmbH, Remshalden, Germany) at $15 \mathrm{~N} / \mathrm{m}^{2}$ for $1 \mathrm{~min}$.

Fabrication of open vial LoD. A PMMA layer $(2 \mathrm{~mm})$ was designed and cut in such a way that it acts as a reservoir when placed above the electrodes patterned on PMMA $(1.5 \mathrm{~mm})$. These two PMMA layers are held together using a layer of PSA. There are three different open vials LoD used in the present study. The open vial LoD-1 was interfaced with large (area $50 \mathrm{~mm}^{2}$ ), while LoD-2 with small (area $0.69 \mathrm{~mm}^{2}$ ) Au electrodes, patterned on PMMA. The open vial LoD-3 has an additional middle layer of PMMA $(0.6 \mathrm{~mm})$ to hold the commercially available screen printed carbon electrode (area $50 \mathrm{~mm}^{2}$ ) (DRP 110, MetrohmDropsens, Llanera, Spain) in place.

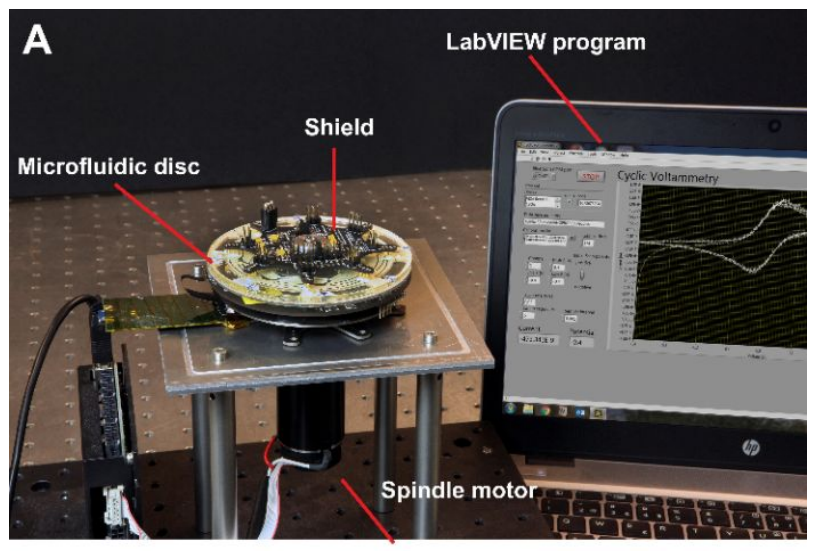

B

Fastening screw

Shield 2WAVEGEN Oscilloscope, Keysight (Santa Rosa, USA)) to generate the reference input voltage $\left(\mathrm{V}_{\mathrm{x}}\right)$. The ADC output is mapped to the reference input current $\left(I_{x}\right)$, since $I_{x}$ is given by dividing $\mathrm{V}_{\mathrm{x}}$ with $\mathrm{R}_{\mathrm{x}}$.

Electrochemical measurements. The electrochemical measurements were performed in a conventional three-electrode setup with both the PoD system and with a commercial potentiostat (CHI660C, CH Instruments Inc., Austin, USA) for comparison, when applicable. Cyclic voltammograms (CVs) were recorded from $-0.4 \mathrm{~V}$ to $+0.4 \mathrm{~V}$ vs. Au pseudo-RE in 1 and 10 $\mathrm{mM}$ potassium ferricyanide ( $\mathrm{FiC}) /$ potassium ferrocyanide ( $\mathrm{FoC}$ ) with phosphate buffered saline (PBS) $(10 \mathrm{mM}$ phosphate, 137 $\mathrm{mM} \mathrm{NaCl}, 2.7 \mathrm{mM} \mathrm{KCl}), \mathrm{pH} \mathrm{7.4}$, as supporting electrolyte, at various scan rates $(10,25,50,100 \mathrm{mV} / \mathrm{sec})$ with open vial LoD1. Square wave voltammetry (SWV) with a step potential of 1 $\mathrm{mV}$, square- wave frequency of $10 \mathrm{~Hz}$ and amplitude of $50 \mathrm{mV}$ was carried out using different concentrations of ascorbic acid from $0.1 \mathrm{M}$ to $10 \mathrm{mM}$ using open LoD-2. CVs were recorded both in static and fluidics, while SWVs were only recording in static condition. Amperometric measurements were carried out both in static and in fluidics (during spin) with custom made $\mathrm{Au}$ electrodes (area $0.69 \mathrm{~mm}^{2}$ ). Detection of paracetamol from 0.15 $\mathrm{mM}$ to $3.3 \mathrm{mM}$ in static was carried out at $+0.55 \mathrm{~V}$ vs. Au pseudo-RE. In addition, calibration in flow during rotation, was performed using amperometric detection with the multi-channel shield, using FiC in the range from $0.1 \mathrm{mM}$ to $10 \mathrm{mM}$ at $-0.4 \mathrm{~V}$ vs. $\mathrm{Au}$ pseudo-RE. The rotation of the LoD at different frequencies $(1$ and $1.5 \mathrm{~Hz})$ was achieved with a spindle motor (RE 35, Maxon motor AG, Sachseln, Switzerland). All chemicals if not otherwise specified were purchased from Sigma Aldrich (St. Louis, USA). Solutions were prepared in ultrapure water (Millipore Corporation, Billerica, USA).

Flow rate measurements. To determine the flow rate, $200 \mu \mathrm{L}$ blue ink (Staedtler, Nürnberg, Germany) dissolved in distilled water (1:1000), was added in the loading chamber. The channel was primed by spinning the disc with a frequency of $12 \mathrm{~Hz}$ for 2 sec. Subsequently, the metering chamber was filled up with fluid by spinning with a lower frequency $(5 \mathrm{~Hz})$. When the metering chamber was completely filled the spinning motor was turned on and images were recorded using a program (PCO Camware 64, PCO AG) as described previously ${ }^{54}$. The obtained raw image data were analyzed using Matlab (R2017a, MathWorks, Natick, USA).

Fabrication and loading of microcontainers. The epoxy-based photoresist SU-8 (SU-8 2075 / SU-8, Microresist Technology $\mathrm{GmbH}$, Berlin, Germany) was used to fabricate the microcontainers with two-steps of photolithography. The microcontainers with an inner diameter of $234,5 \mu \mathrm{M}$ and a depth of $211,0 \mu \mathrm{M}$, were fabricated on top of a Teflon coated silicon wafer (4-in. b100N n-type, Okmetic, Finland) ${ }^{55,56}$. After fabrication, the wafers were cut into chips $\left(12.8 \times 12.8 \mathrm{~mm}^{2}\right)$, with 625 microcontainers/chip, using laser micromachining tool (microSTRUCT vario, 3D Microac AG, Germany). The FiC was loaded in the microcontainers by powder embossing. The excess $\mathrm{FiC}$ in between the microcontainers was removed with pressurized air.

Release monitoring from microcontainers. Initially, the microchannel was primed ( $12 \mathrm{~Hz}$ for $2 \mathrm{sec})$ with $100 \mu \mathrm{L}$ PBS, followed by filling up $(5-6 \mathrm{~Hz})$ of the metering chamber with 50 $\mu \mathrm{L}$ PBS for precise volume control. The microcontainers filled with FiC were scraped off the Teflon/silicon wafers and $1 / 4$ of the chip (approximately 156 microcontainers) inserted in the access hole with spatula, followed by the addition of $150 \mu \mathrm{L}$ PBS in the loading chamber. The electrochemical detection was carried out during priming in the absence of electrochemically active compound (FiC) (for baseline) with PBS, and during rotation in the presence of loaded microcontainers, at $1.5 \mathrm{~Hz}$.

Data acquisition software and data analysis. During the experiment with $\mathrm{PoD}$, the generated data was transmitted via Bluetooth to a Windows PC. The data was plotted live and 
displayed in the custom made LabVIEW (National Instruments, Austin, USA) program. After experiments, the data file was saved in text format automatically with a time stamp and technique name. The obtained raw data from the developed potentiostat was treated using Savitzky-Golay method with 30 points averaging. Origin 2018b (OriginLab Corp., Northampton, USA) was used to analyze and display the data. For the calibration curves the peak heights (SWV) and current changes (amperometry) were obtained either using the CHI data analysis software or Origin $2018 \mathrm{~b}$ (PoD).

\section{RESULTS AND DISCUSSION}

Design of the PoD unit. The PoD was designed to be versatile for centrifugal microfluidics-based application. The modular structure of the device enables direct, effortless, and robust interfacing with the electrodes optical observation of the reaction chamber and provides the possibility for further instrumental development, with compatible functional units.

As depicted in Figure 1A, the PoD detection unit is composed of three main functional parts: (i) a $5 \mathrm{~V}-250 \mathrm{kHz}$ Qi-based wireless power supply, (ii) a core circuit (platform) and (iii) a module (shield). The device works in stream processing and can be controlled by any external device such as a smartphone (Android studio) and a PC (LabVIEW) through Bluetooth communication. At every iteration, a DAC output signal is generated and an ADC sample is collected.

The core circuit, called platform (Figure 1B) houses the main potentiostat features. It is composed of a single channel 14-bits DAC, which controls the potential of the WE vs. RE as well as a 14-bits SAR ADC for high speed/high resolution data sample. The function of the ATmega 2560 microcontroller is to operate the device, while the serial interface enables to programming of the microcontroller. In addition, a HC-05 Bluetooth module is used for wireless data communication and a 16-pin header interface facilitates the connection of the platform to the specific module (shield).

The shield was mounted above the microfluidic disc and has been designed such that it permits the imaging of the LoD device during rotation, with minimal obstruction of the fluidics view. This part of the PoD can be configured when adding complementary features (e.g. multiplexing) to the detection unit, and contains a three-electrode potentiostat circuit in the three operational amplifier/buffered reference configuration with 24 spring-loaded connectors for direct short path connection between the potentiostat and the electrodes (Figure S1A). The 24 spring loaded pins enables connection to a maximum of 8 electrode arrays, each array composed of three electrodes (WE, RE and $\mathrm{CE}$ ). As indicated in Figure 1C, the shield is equipped with a switch to select the current range of the measurement. Additionally, a multi-channel application specific shield (Figure S1B) was also developed to enable four electrochemical measurements at the same time.

Evaluation of the performance of the PoD. The potentiostat has been designed to perform commonly used electrochemical detection techniques, such as $\mathrm{CV}, \mathrm{SWV}$ and chronoamperometry. However, other electrochemical techniques can be easily programmed via a custom made LabVIEW program when required. The experimental set-up is presented in Figure 2A. During experiment the PoD was placed on stage and connected to a spindle motor controlled by custom-made software in a LabVIEW environment. The assembly of the system and the concept of the modular design is depicted in Figure 2B, showing the four main functional parts: a power source, a platform, a fluidic disc with integrated electrodes and a shield.

The performance of the $\mathrm{PoD}$ was evaluated as described in details in the Material and methods section. The PoD, with power rating of $850 \mathrm{~mW}$, enables the generation of DC voltage range between $\pm 1 \mathrm{~V}$ at a resolution of $200 \pm 40 \mu \mathrm{V}$ having the possibility to manually choose the transimpedance gain $(10 \mathrm{k} \Omega, 100 \mathrm{k} \Omega, 1 \mathrm{M} \Omega$, $10 \mathrm{M} \Omega$ ).
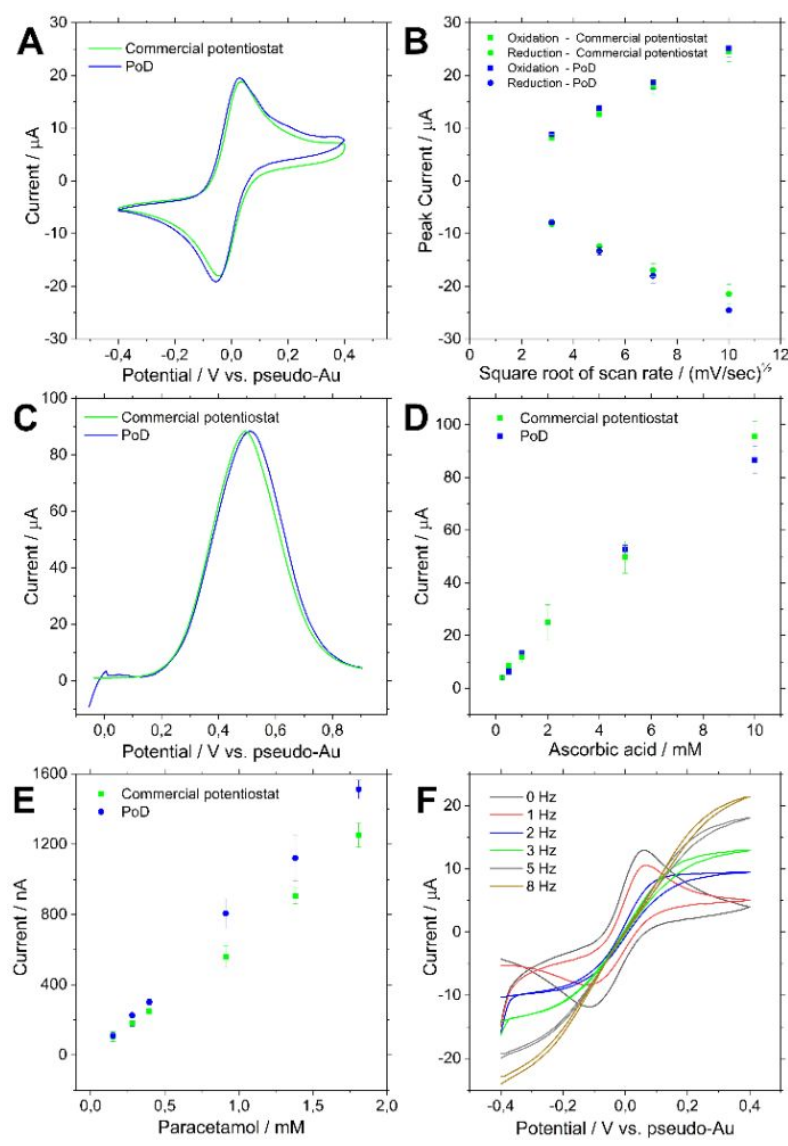

Figure 3. (A) Representative CVs of $1 \mathrm{mM} \mathrm{FiC}$ with $\mathrm{PoD}$ and commercial potentiostat, Au WE area: $50 \mathrm{~mm}^{2}$, applied potential vs. pseudo Au-RE, Au-CE. The CVs were performed at a scan rate of $50 \mathrm{mV} / \mathrm{sec}$; (B) Oxidation and reduction peak currents as a function of the square root of the scan rate; (C) SWVs of $10 \mathrm{mM}$ ascorbic acid, (Carbon WE area: $50 \mathrm{~mm}^{2}$, applied potential vs. Ag-RE, carbon CE). The SWVs were recorded with a potential step $0.004 \mathrm{~V}$, frequency $10 \mathrm{~Hz}$, amplitude $0.025 \mathrm{~V}$; (D) Calibration plot recorded for different concentrations of ascorbic acid; (E) Calibration curve of paracetamol obtained with PoD and commercial potentiostat, using $\mathrm{Au}$ WE (area: $50 \mathrm{~mm} 2$ ), $\mathrm{Au}-\mathrm{CE}$ and Au-RE. Applied potential +0.4 V vs. pseudo Au-RE; (F) CVs were recorded at various rotation speeds at $100 \mathrm{mV} / \mathrm{sec}$ scan rate in $1 \mathrm{mM} \mathrm{FiC}, \mathrm{Au} \mathrm{WE}$ area: $0.69 \mathrm{~mm} 2$, applied potential vs. pseudo Au-RE, Au-CE. All measurements were performed in PBS as supporting electrolyte, $\mathrm{pH} 7.4$ and standard deviations were calculated based on triplicates $(n=3)$.

The measurable current range can vary from $\pm 400 \mathrm{nA}$ to $\pm 400 \mu \mathrm{A}$ depending on the used gain, with a measured current resolution of $200 \mathrm{pA}$ at $10 \mathrm{M} \Omega$ gain setting (Table S1).

We found that the standard deviation of the measured current was $0.075 \%$ (of the range) for $10 \mathrm{M} \Omega$ and $0.03 \%$ (of the range) for 10 $\mathrm{k} \Omega, 100 \mathrm{k} \Omega$ and $1 \mathrm{M} \Omega$ gain. Due to the sampling rate of $25 \mathrm{~ms}$ the maximum scan rate for $\mathrm{CV}$ was $\Delta \mathrm{V} \cdot 1000 / 25 \mathrm{~V} / \mathrm{s}$ and the maximum frequency for SWV was $20 \mathrm{~Hz} . \Delta \mathrm{V}$ is the parameter (voltage resolution) defined by the user in the program which in turn controls the voltage step of the DAC, $\Delta \mathrm{V}$ does not necessarily coincides with the minimum. While the time (sec) is defined by the sum of time taken for the transfer of a single 
sample data between the computer to PoD via Bluetooth, signal propagation time through the $\mathrm{PoD}$ and the time for conversion and plotting in real-time.

The electrochemical performance of the potentiostat was evaluated both in static and flow condition. All static measurements were performed in open vial LoD systems (Figure S2). An open vial LoD system can be used for electrochemical characterization as well as for calibration ${ }^{54}$.

SWV is a well-accepted voltammetric technique for quantitative measurements ${ }^{57}$. Ascorbic acid (vitamin C) is an antioxidant, commonly used in the food industry, since addition of ascorbic acid averts undesired changes in flavor and color. Therefore, monitoring ascorbic acid for quality control is very important 58,59 . SWVs were recorded with commercially available carbon electrodes in the open vial LoD-3 (Figure S2C), using different concentrations of ascorbic acid from $500 \mu \mathrm{M}$ to $10 \mathrm{mM}$. The SWVs presented in Figure $3 \mathrm{C}$, are the signals from $10 \mathrm{mM}$ ascorbic acid recorded with commercial potentiostat and PoD. Figure 3D presents the comparison of the data collected with both potentiostats and shows that the signal recorded with PoD was comparable with the data obtained with the commercial system. In addition we performed amperometric measurements with paracetamol, an electrochemically active drug, commonly used for pain and fever relief 60 and is commonly detected using electrochemical techniques 61,62 . Due to its continuous use in large scale, paracetamol has become one of the most prominent contaminants in water bodies and it has been shown that excessive intake of this compound can cause hepatotoxicity ${ }^{63,64}$. The experiment was performed in a static condition by successive addition of paracetamol in the reservoir of the open vial LoD-2 (Figure S2B). We found a good comparison between the values obtained from the $\mathrm{PoD}$ and commercial potentiostat as seen in Figure 3E.

The light weight design of the PoD is especially important when performing measurement during rotation, since the weight of the device can greatly affect the inertia during spinning ${ }^{52}$. The modular nature of the PoD helps in distributing the weight by combining the platform (108 g) and the disk holder (26 g), thus displacing the center of gravity more towards the spindle motor. The shield weighing $19 \mathrm{~g}$, is the only weight placed on top of the LoD device.

We evaluated the performance of the PoD during rotation and compared the baseline noise, with the data recorded using the commercial potentiostat, in PBS at applied potential of $+0.4 \mathrm{~V}$ vs. pseudo-Au-RE. The connection of the electrodes to the commercial potentiostat was achieved with a slip ring (SRS110073, Penlink, Sweden) as shown in Figure S3, a method commonly used when connecting electrochemical sensors in centrifugal microfluidics ${ }^{31,35,39}$. Both the PoD interfaced with the electrodes in the LoD and the commercial potentiostat connected through a slip ring were rotated at 1,2,3,5,8 and $10 \mathrm{~Hz}$. The raw signal, as recorded with the PoD, without any internal filtering is shown in Figure 4, in comparison with the data obtained from the software of the commercial potentiostat. We observed that at lower rotation speeds $(1$ and $2 \mathrm{~Hz})$ the baseline current is comparable in both instruments. Despite using raw data, the acceleration and deceleration of $\mathrm{PoD}$ causes low noise $(\approx 3-6$ $\mathrm{nA})$. At higher rotation speeds we recoded higher peaks in the signal with the PoD, than with the commercial potentiostat. The electrochemical baseline noise, recorded as peaks are due to the movement of PBS over the electrode surface as a result of inertia when changing the speed of rotation. The lack of peaks at 3 and 5 $\mathrm{Hz}$ and the lower peaks in the baseline recorded with the commercial potentiostat is probably due to the internal noise filtering while converting analog signals to digital (ADC) during data acquisition. Based on our experiments, the observed noise during acceleration and deceleration recorded with both instruments is mostly electrochemical and not instrumental.
The presented data in the manuscript was treated using the Savitzky-Golay method as described in the 'Data acquisition software and data analysis' section and there was no need for any fast Fourier transform data treatment as reported by Bauer et al. ${ }^{52}$

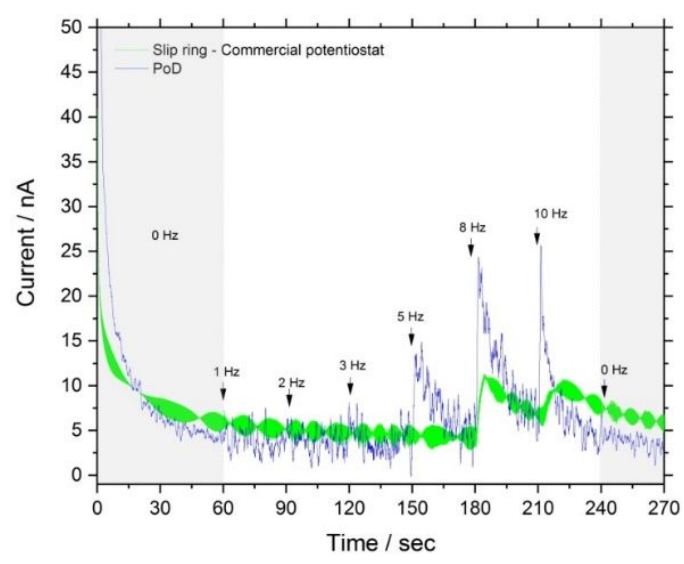

Figure 4. Baseline noise measured during rotation in fluidics using PBS at applied potential of $+0.4 \mathrm{~V}$ vs. pseudo-Au-RE recorded with PoD and commercial potentiostat using the $\mathrm{Au}$ electrodes (WE area: $0.69 \mathrm{~mm} 2$, pseudo-Au-RE, $\mathrm{Au} \mathrm{CE}$ ) patterned on PMMA.

Considering that the maximum baseline noise recorded in PBS was $6 \mathrm{nA}$, the theoretical lowest measurable signal at limit of detection, would be $18 \mathrm{nA}(\mathrm{S} / \mathrm{N}=3)$. In our experiments the lowest measured signal for an analyte was $45 \mathrm{nA}$ in static (Figure $3 \mathrm{E}$ ) and $100 \mathrm{nA}$ in flow (Figure 5A). However, as it can be seen in Figure 5A, measuring lower electrochemical signal then $45 \mathrm{nA}$ is feasible.

$\mathrm{CVs}$ were also recorded at different rotational frequencies (Figure $3 \mathrm{~F}$ ) using electrodes integrated in the fluidic system (Figure 6). We observed that at 0 and $1 \mathrm{~Hz}$ the reaction is diffusion limited, while at rotation speeds at and above $2 \mathrm{~Hz}$ the curve in is reaction limited due to mass transfer as has also been reported previously 52.

So far, in the case of LoD systems multiple electrochemical measurements during rotation, were only feasible when connecting the electrodes in the fluidic system to a multichannel potentiostat through a slip ring ${ }^{37}$. In the presented $\mathrm{PoD}$, multichannel detection capability was also implemented using the multichannel shield (Figure S1B). The amperometric detection presented in Figure 5A was performed with four electrodes at the same time during rotation.

Previously in an electrochemical LoD device, it has been shown that an increase in flow rate results in increased current response 39. We evaluated the effect of rotational frequency on amperometric measurements. As it can be seen in Figure 5A and $5 \mathrm{~B}$ the current arising from the electrochemical reduction of $\mathrm{FiC}$ increased when increasing the flow rate. We recorded the same behavior when working with paracetamol (Figure S5). This effect was proposed and used for increasing the sensitivity of electrochemical detection ${ }^{39,52}$.

Real-time release from drug delivery microdevices. Dissolution and release of drugs are of high importance in the development phase of new oral drug formulations and delivery systems ${ }^{65,66}$. For a drug to be absorbed after oral administration, it needs to be dissolved before it can pass the intestinal membrane and be absorbed into the bloodstream. For being able to deliver more drugs by the oral route, novel oral drug delivery systems are needed. One such system is the polymeric microcontainers which 
serve to protect the drug through the stomach followed by a drug release in the intestine ${ }^{67-69}$. Such devices are increasingly utilized for drug delivery ${ }^{67,70,71}$, and it is essential to characterize them
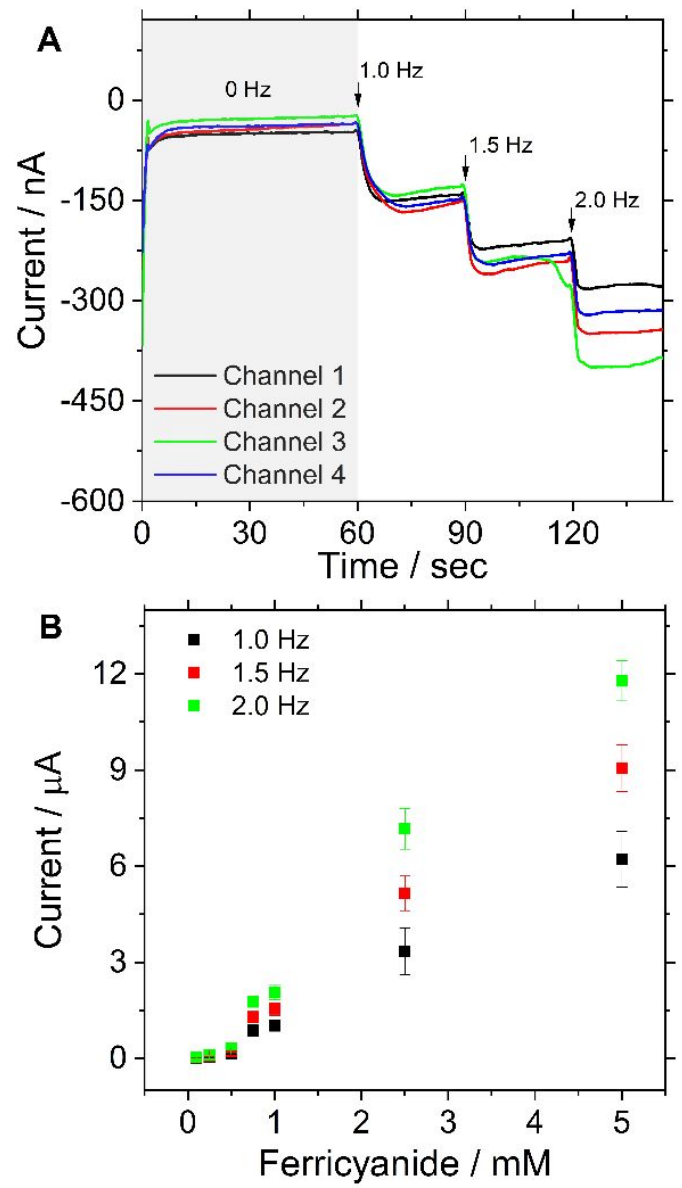

(e.g. release studies).

Figure 5. (A) Multichannel amperometric measurement in the LoD platform of $500 \mu \mathrm{M} \mathrm{FiC} \mathrm{in} \mathrm{PBS,} \mathrm{pH} 7.4$ as supporting electrolyte at an applied potential of $-0.4 \mathrm{~V}$ vs. pseudo-Au RE, using on PMMA patterned Au electrodes (WE area: $0.69 \mathrm{~mm} 2$, pseudo Au-RE, Au CE) under 1, 1.5 and $2 \mathrm{~Hz}$; (B). Calibration plot, showing the normalized current changes, recorded for different concentrations of FiC during rotation at $1,1.5$ and $2 \mathrm{~Hz}$, $(n=3)$.

Most of the current setups for studying drug release from micro devices such as microcontainers are not appropriate, as the volumes are very large compared to the quantity of drug in the devices. Therefore, it is essential to exploit new ways to investigate drug release in much smaller volumes and thereby, also more relevant compared to the in vivo situation ${ }^{67,72}$.

The microfluidic disc developed for monitoring drug release from microdevices is composed of four PMMA layers (Figure 6A, layer 1, 3, 5 and 7) of which the bottom PMMA layer (layer 7) contains the patterned Au electrode arrays. The three layers of PSA (Figure 6A, layer 2, 4 and 6) are used for assembling the PMMA layers. The fully assembled LoD device with eight measurement units is shown in Figure 6B. Each unit has three main functional parts: (i) loading chamber with embedded filters and access holes used for the addition of liquids and microdevices; (ii) microchannel connecting the loading and the metering chamber, with integrated Au electrode array (WE, CE,
$\mathrm{RE}$ ); and (iii) metering and waste chamber (Figure 6C). The dimension of the microchannel along with the spinning speed defines the flow rate, while the embedded filter with pores of 160 $\mu \mathrm{M} \varnothing$, with $0.5 \mathrm{~mm}$ spacing, and physically prevents the microdevices from entering the microchannel during release studies. The metering chamber is designed to hold a volume of 50 $\mu \mathrm{L}$. The metering chamber is useful to collect the fluids during priming which usually requires a high burst frequency $(12 \mathrm{~Hz})$. After the overflow of $50 \mu \mathrm{L}$ in the metering chamber, a uniform flow rate can be established at lower flow rates $(1-2 \mathrm{~Hz})$.

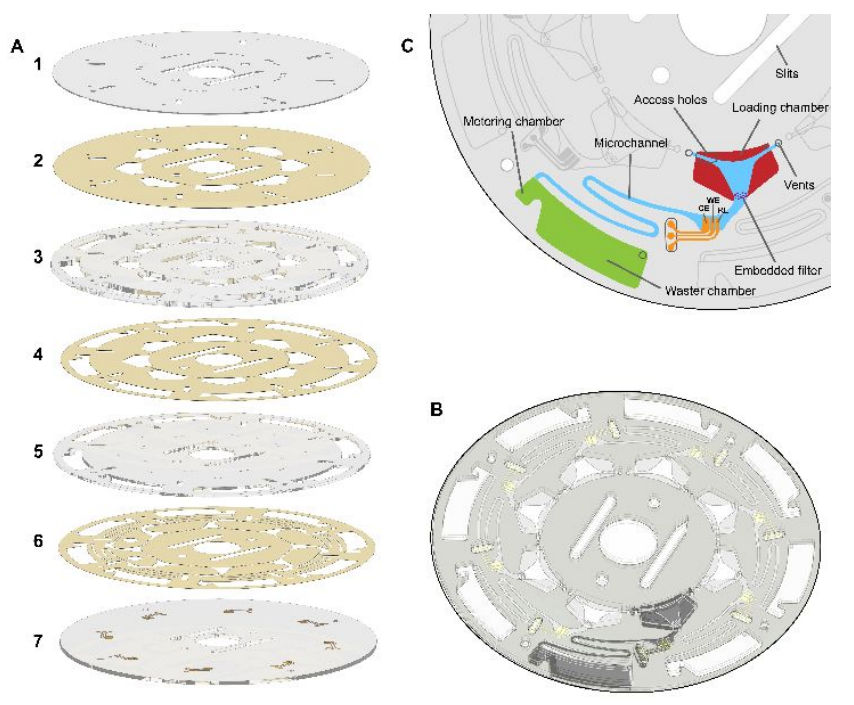

Figure 6. (A) Exploded view of the microfluidic disc; (B) View of the assembled microfluidic disc, with a highlighted measurement unit; (C) A cartoon showing one measurement unit with its functional parts.

In order to use the LoD system for drug release studies, the flow rate in the microfluidic channel needs to be evaluated. Given that the working volumes in the fluidic system are in the range of a few $100 \mu \mathrm{L}$, the assay needs to be performed at relatively low rotation frequencies to enable real-time detection of drug release for longer durations. The flow rates were evaluated optically using a MATLAB program and the results were compared with theoretically calculated values (Supplementary information).

One of the main challenges when developing the LoD device was to obtain a reliable and controllable flow at low (below 10 $\mu \mathrm{L} / \mathrm{min}$ ) flow rate in order to be able to perform real-time release studies, using small amounts of microdevices in a relatively low volume (approx. $100 \mu \mathrm{L}$ ). Figure 7A shows, the correlation between flow rate and rotational frequency, comparing experimental and theoretical values. We found that in the developed LoD we can achieve flow rates in the range of 1-10 $\mu \mathrm{L} /$ min enabling a total assay time from 10 up to $100 \mathrm{~min}$, considering $100 \mu \mathrm{L}$ volume in the loading chamber.

We observed that the thickness of the used PSA layer is crucial when aiming for precise control of the flow rate. There were substantial differences between measured and theoretically calculated higher hydraulic resistance due to the PSA being pressed in the microchannels during the assembly process (calculations provided in Supplementary material).

The real-time release was evaluated from the microcontainers ( 50 microcontainers) loaded with $\mathrm{FiC}$. The porous feature i.e., filters on PMMA, in the bottom of the chamber (layer 5. Figure 6A), physically prevented the microcontainers from blocking the channels leading to the detection chamber during spin. At $-0.4 \mathrm{~V}$ (vs. Au pseudo Au-RE) FiC is reduced and the resultant 
electrochemical signal was recorded. After the fluidic system was primed, a baseline was recorded in a static condition for $30 \mathrm{sec}$ in PBS, before the rotational frequency was set to $2 \mathrm{~Hz}$. In a similar manner, we followed the dissolution of $50 \mu \mathrm{L} \mathrm{FiC} \mathrm{solution} \mathrm{(10}$ $\mathrm{mM}$ ) respectively. Figure 7B shows the stable baseline recorded with PBS as well as the dissolution and release curves as current vs. time. The release of $\mathrm{FiC}$ from microcontainers (blue curve) results in an initial high current indicating burst release as
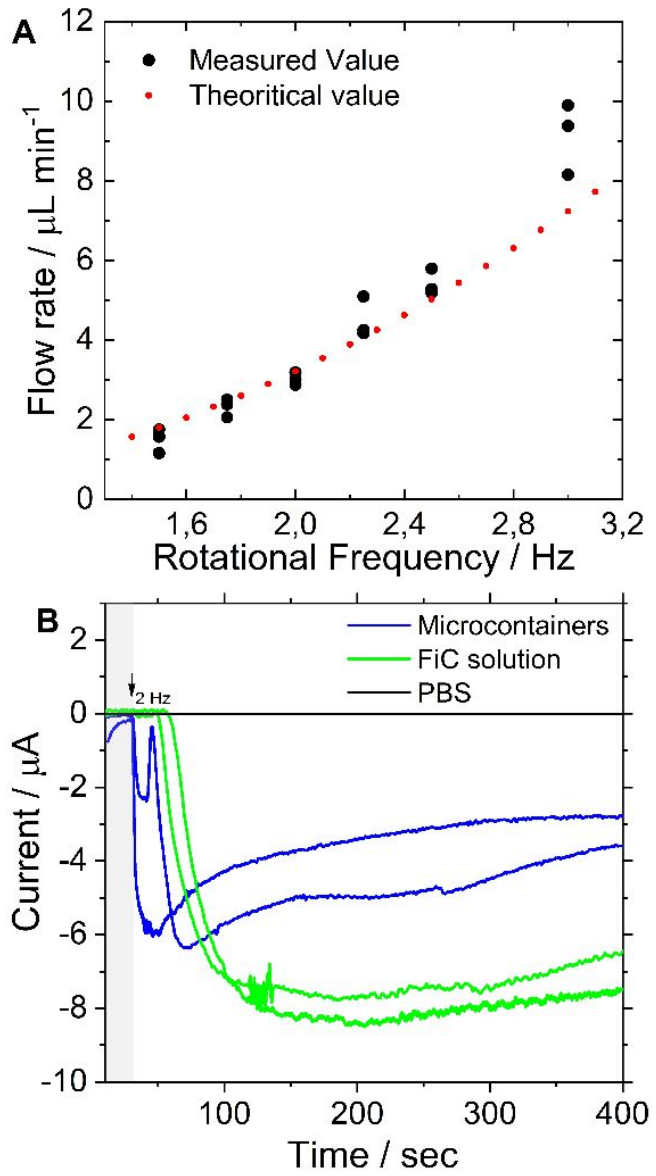

Figure 7. (A) Optical measurements of flow rate vs. rotation frequency $(\mathrm{n}=3)$, for LoD platforms with microchannels in $86 \mu \mathrm{m}$ thick PSA; (B) Amperometric release and dissolution of $\mathrm{FiC}$ in PBS, pH 7.4 as supporting electrolyte, at a potential of $+0.4 \mathrm{~V}$ vs. $\mathrm{Au}$ pseudo-RE. PMMA patterned fabricated gold $\mathrm{Au}$ electrodes (WE area: $0.69 \mathrm{~mm} 2$, pseudo Au-RE, Au CE).

previously reported ${ }^{69}$. When measuring release from microcontainers, in one of the curves, a small current fluctuation is seen for about 8 seconds. This may be due to a momentary reorientation of microcontainers during release.

From the stabilized current at $400 \mathrm{sec}$, we can estimate the amount of released $\mathrm{FiC}$ to be $1.25 \mathrm{mM}$, based on the calibration curve presented in Figure 5B. In addition, the current profile measured from the FiC solution (green curve) is different, as burst release is not seen, which is expected considering the mixing of the FiC with PBS in the loading chamber. The concentration in this case calculated based on the calibration curve in flow (Figure 5B) is $2.5 \mathrm{mM}$ as anticipated considering the dilution in the loading chamber. The release of FiC from the microcontainers mimics the situation of drug delivery from these devices, while the dissolution of solution is a simplified case of free drug. This application as an example demonstrates the ability to measure on-line and in-flow during spinning.

\section{CONCLUSION}

We present for the first time, a modular, lightweight, wirelessly powered potentiostat-on-a-disc for centrifugal microfluidic applications. The developed device provides a practical solution to one of the trivial interfacing challenges during spinning. The presented results demonstrates the performance of the developed device on par with a commercial potentiostat. Considering the shield design which enables visibility of the fluidics during spinning opens up the possibility for real-time optical detection in the future. The flexibility and modularity of the system provides room for implementation of additional electrochemical techniques (e.g. linear sweep voltammetry, differential pulse voltammetry, impedance spectroscopy).

The developed potentiostat in combination with the microfluidic systems, designed for drug dissolution and release studies, opens new avenues for drug delivery studies from drug delivery microdevices. The PoD in combination with the presented microfluidic disc could be used for the investigation of drug release profiles from microdevices with various polymer coatings (e.g. $\mathrm{pH}$-sensitive polymers). In addition, the portability of the PoD coupled with custom designed LoD unit can be applied for on-site detection (e.g. environmental analysis) or point of care application in diagnostics.

\section{ASSOCIATED CONTENT}

\section{Supporting Information}

The Supporting Information is available free of charge on the ACS Publications website.

Complementary information about the shield modularity and details about the multi-channel shield, table summarizing the PoD performance, photos of the used open vial LoD systems, experimental setup for noise measurement with commonly used slip ring system. Calculation of the theoretical flow rate and show the comparison of calculated and measured flow rate values using $140 \mu \mathrm{m}$ pressure sensitive adhesive film and electrochemical detection of paracetamol in the LoD platform during rotation (PDF).

\section{AUTHOR INFORMATION}

\section{Corresponding Authors}

\section{* E-mail: stran@dtu.dk \\ * E-mail: kinzo@dtu.dk \\ ORCID}

Sriram Thoppe Rajendran: 0000-0003-3667-0834

Kinga Zór: 0000-0002-2905-4155

Notes

The authors declare no competing financial interest.

\section{ACKNOWLEDGEMENT}

We acknowledge Jen-Hung Wang for his contribution in the early stage of android application development, Jeppe Rahbæk Mosgaard for his support in the electronics workshop. We thank Jesper Scheel and Ellen Vallentin Christiansen for photos and graphical design. This work was supported by the Danish 
National Research Foundation (DNRF122) and Villum Fonden (Grant No. 9301) for Intelligent Drug delivery and sensing Using microcontainers and Nanomechanics (IDUN).

\section{REFERENCES}

(1) Bakker, E.; Telting-Diaz, M. Electrochemical Sensors. Anal. Chem. 2002, 74 (12), 2781-2800.

(2) Castillo, J.; Gáspár, S.; Leth, S.; Niculescu, M.; Mortari, A.; Bontidean, I.; Soukharev, V.; Dorneanu, S. A.; Ryabov, A. D.; Csöregi, E. Biosensors for Life Quality - Design, Development and Applications. Sensors Actuators, B Chem. 2004, 102 (2), 179-194.

(3) Chen, A.; Chatterjee, S. Nanomaterials Based Electrochemical Sensors for Biomedical Applications. Chem. Soc. Rev. 2013, 42 (12), 5425.

(4) Mannino, S.; Wang, J. Electrochemical Methods for Food and Drink Analysis. Electroanalysis 1992, 4 (9), 835-840.

(5) Rotariu, L.; Lagarde, F.; Jaffrezic-Renault, N.; Bala, C. Electrochemical Biosensors for Fast Detection of Food Contaminants - Trends and Perspective. TrAC Trends Anal. Chem. 2016, 79, 8087.

(6) Hanrahan, G.; Patil, D. G.; Wang, J. Electrochemical Sensors for Environmental Monitoring: Design, Development and Applications. J. Environ. Monit. 2004, 6 (8), 657.

(7) Mora, L.; Chumbimuni-Torres, K. Y.; Clawson, C.; Hernandez, L.; Zhang, L.; Wang, J. Real-Time Electrochemical Monitoring of Drug Release from Therapeutic Nanoparticles. $J$. Control. Release 2009, 140 (1), 69-73.

(8) Caviglia, C.; Zór, K.; Montini, L.; Tilli, V.; Canepa, S.; Melander, F.; Muhammad, H. B.; Carminati, M.; Ferrari, G.; Raiteri, R.; et al. Impedimetric Toxicity Assay in Microfluidics Using Free and Liposome-Encapsulated Anticancer Drugs. Anal. Chem. 2015, 87 (4), 2204-2212.

(9) Lab-on-a-Chip Devices and Micro-Total Analysis Systems; Castillo-León, J., Svendsen, W. E., Eds.; Springer International Publishing: Cham, 2015.

(10) Nyholm, L. Electrochemical Techniques for Lab-on-aChip Applications. Analyst 2005, 130 (5), 599.

(11) da Silva, E. T. S. G.; Souto, D. E. P. P.; Barragan, J. T. C. C.; de F. Giarola, J.; de Moraes, A. C. M.; Kubota, L. T.; da Silva, E. T. S. G.; Souto, D. E. P. P.; Barragan, J. T. C. C.; de F. Giarola, J.; et al. Electrochemical Biosensors in Point-of-Care Devices: Recent Advances and Future Trends. ChemElectroChem 2017, 4 (4), 778 794.

(12) Patou, F.; Alzahra, F.; Kjægaard, C.; Dimaki, M.; Madsen, J.; Svendsen, W. E. Evolvable Smartphone-Based Platforms for Point-Of-Care In-Vitro Diagnostics Applications. Diagnostics 2016, $6(3), 1-18$

(13) Kassal, P.; Kim, J.; Kumar, R.; De Araujo, W. R.; Steinberg, I. M.; Steinberg, M. D.; Wang, J. Smart Bandage with Wireless Connectivity for Uric Acid Biosensing as an Indicator of Wound Status. Electrochem. commun. 2015, 56, 6-10.

(14) Xu, X.; Zhang, S.; Chen, H.; Kong, J. Integration of Electrochemistry in Micro-Total Analysis Systems for Biochemical Assays: Recent Developments. Talanta 2009, 80 (1), 8-18.

(15) Sassa, F.; Morimoto, K.; Satoh, W.; Suzuki, H. Electrochemical Techniques for Microfluidic Applications. Electrophoresis 2008, 29 (9), 1787-1800.

(16) Vergani, M.; Carminati, M.; Ferrari, G.; Sampietro, M.; Amato, L.; Heiskanen, A.; Dimaki, M.; Svendsen, W. E.; Emneus, J. Compact Potentiostat for Cellular Electrochemical Imaging with 54 Parallel Channels. 2012 IEEE Biomed. Circuits Syst. Conf. Intell. Biomed. Electron. Syst. Better Life Better Environ. BioCAS 2012 Conf. Publ. 2012, 136-139.

(17) Cruz, A. F. D.; Norena, N.; Kaushik, A.; Bhansali, S. A Low-Cost Miniaturized Potentiostat for Point-of-Care Diagnosis. Biosens. Bioelectron. 2014, 62 (June), 249-254.
(18) Xu, Y.; Yung, L. H. K.; Lee, Y. X. T. M. Low Cost Fabrication of Microelectrodes on Plastic Substrate. Microsyst. Technol. 2011, 361-366.

(19) Rowe, A. A.; Bonham, A. J.; White, R. J.; Zimmer, M. P.; Yadgar, R. J.; Hobza, T. M.; Honea, J. W.; Ben-Yaacov, I.; Plaxco, K. W. Cheapstat: An Open-Source, "Do-It-Yourself" Potentiostat for Analytical and Educational Applications. PLoS One 2011, 6 (9).

(20) Smith, S.; Mager, D.; Perebikovsky, A.; Shamloo, E.; Kinahan, D.; Mishra, R.; Torres Delgado, S. M.; Kido, H.; Saha, S.; Ducrée, J.; et al. CD-Based Microfluidics for Primary Care in Extreme Point-of-Care Settings. Micromachines 2016, 7 (2), 1-32.

(21) Burger, R.; Kirby, D.; Glynn, M.; Nwankire, C.; O'Sullivan, M.; Siegrist, J.; Kinahan, D.; Aguirre, G.; Kijanka, G.; Gorkin, R. A.; et al. Centrifugal Microfluidics for Cell Analysis. Curr. Opin. Chem. Biol. 2012, 16 (3-4), 409-414.

(22) Maguire, I.; Kennedy, R. O.; Regan, F.; Ducrée, J.; Regan, F. A Review of Centrifugal Micro Fl Uidics in Environmental Monitoring. Anal. Methods 2018, 10, 1497.

(23) Ducrée, J.; Haeberle, S.; Lutz, S.; Pausch, S.; Von Stetten, F.; Zengerle, R. The Centrifugal Microfluidic Bio-Disk Platform. $J$. Micromechanics Microengineering 2007, 17 (7).

(24) Strohmeier, O.; Keller, M.; Schwemmer, F.; Zehnle, S.; Mark, D.; von Stetten, F.; Zengerle, R.; Paust, N. Centrifugal Microfluidic Platforms: Advanced Unit Operations and Applications. Chem. Soc. Rev. 2015, 44 (17), 6187-6229.

(25) Madou, M.; Zoval, J.; Jia, G.; Kido, H.; Kim, J.; Kim, N LAB ON A CD. Annu. Rev. Biomed. Eng. 2006, 8 (1), 601-628.

(26) Mark, D.; Haeberle, S.; Günter, A.; Roth, G.; Felix Von Stettenz, A.; Zengerlez, R. Microfluidic Lab-on-a-Chip Platforms: Requirements, Characteristics and Applications. Chem. Soc. Rev. 2010, 39, 1153-1182.

(27) Durucan, O.; Rindzevicius, T.; Schmidt, M. S.; Matteucci, M.; Boisen, A. Nanopillar Filters for Surface-Enhanced Raman Spectroscopy. ACS Sensors 2017, 2 (10), 1400-1404.

(28) Morelli, L.; Serioli, L.; Centorbi, F. A.; Jendresen, C. B.; Matteucci, M.; Ilchenko, O.; Demarchi, D.; Nielsen, A. T.; Zór, K.; Boisen, A. Injection Molded Lab-on-a-Disc Platform for Screening of Genetically Modified: E. Coli Using Liquid-Liquid Extraction and Surface Enhanced Raman Scattering. Lab Chip 2018, 18 (6).

(29) Uddin, R.; Burger, R.; Donolato, M.; Fock, J.; Creagh, M.; Fougt, M.; Boisen, A. Lab-on-a-Disc Agglutination Assay for Protein Detection by Optomagnetic Readout and Optical Imaging Using Nano- and Micro- Sized Magnetic Beads. Biosens. Bioelectron. 2016, $85,351-357$.

(30) King, D.; Osullivan, M.; Ducrée, J. Optical Detection Strategies for Centrifugal Microfluidic Platforms. J. Mod. Opt. 2014, $61(2), 85-101$

(31) Abi-Samra, K.; Kim, T. H.; Park, D. K.; Kim, N.; Kim, J.; Kim, H.; Cho, Y. K.; Madou, M. Electrochemical Velocimetry on Centrifugal Microfluidic Platforms. Lab Chip 2013, 13 (16), 3253 3260 .

(32) Ramachandraiah, H.; Amasia, M.; Cole, J.; Sheard, P.; Pickhaver, S.; Walker, C.; Wirta, V.; Lexow, P.; Lione, R.; Russom, A. Lab-on-DVD: Standard DVD Drives as a Novel Laser Scanning Microscope for Image Based Point of Care Diagnostics. Lab Chip 2013, 13 (8), 1578-1585

(33) Rattanarat, P.; Teengam, P.; Siangproh, W.; Ishimatsu, R.; Nakano, K.; Chailapakul, O.; Imato, T. An Electrochemical Compact Disk-Type Microfluidics Platform for Use as an Enzymatic Biosensor. Electroanalysis 2015, 27 (3), 703-712.

(34) Nwankire, C. E.; Venkatanarayanan, A.; Glennon, T.; Keyes, T. E.; Forster, R. J.; Ducrée, J. Label-Free Impedance Detection of Cancer Cells from Whole Blood on an Integrated Centrifugal Microfluidic Platform. Biosens. Bioelectron. 2015, 68 , $382-389$.

(35) Andreasen, S. Z.; Kwasny, D.; Amato, L.; Brøgger, A. L.; Bosco, F. G.; Andersen, K. B.; Svendsen, W. E.; Boisen, A. Integrating Electrochemical Detection with Centrifugal Microfluidics for Real-Time and Fully Automated Sample Testing. RSC Adv. 2015, 5 (22), 17187-17193.

(36) Cho, H. K.; Lee, Y. H.; Couch, R. A.; Jagadeesh, J. M.; 
Olson, C. L. Development of a Multichannel Electrochemical Centrifugal Analyzer. Clin. Chem. 1982, 28 (9), 1956-1961.

(37) Sanger, K.; Zór, K.; Bille Jendresen, C.; Heiskanen, A.; Amato, L.; Toftgaard Nielsen, A.; Boisen, A. Lab-on-a-Disc Platform for Screening of Genetically Modified E. Coli Cells via Cell-Free Electrochemical Detection of p-Coumaric Acid. Sensors Actuators, B Chem. 2017, 253, 999-1005.

(38) Li, T.; Fan, Y.; Cheng, Y.; Yang, J. An Electrochemical Lab-on-a-CD System for Parallel Whole Blood Analysis. Lab Chip 2013, 13 (13), 2634.

(39) Kim, T.-H.; Abi-Samra, K.; Sunkara, V.; Park, D.-K.; Amasia, M.; Kim, N.; Kim, J.; Kim, H.; Madou, M.; Cho, Y.-K. Flow-Enhanced Electrochemical Immunosensors on Centrifugal Microfluidic Platforms. Lab Chip 2013, 13 (18), 3747.

(40) Höfflin, J.; Torres Delgado, S. M.; Suárez Sandoval, F.; Korvink, J. G.; Mager, D. Electrifying the Disk: A Modular Rotating Platform for Wireless Power and Data Transmission for Lab on a Disk Application. Lab Chip 2015, 15 (12), 2584-2587.

(41) Nwankire, C. E.; Czugala, M.; Burger, R.; Fraser, K. J.; Connell, T. M.; Glennon, T.; Onwuliri, B. E.; Nduaguibe, I. E.; Diamond, D.; Ducr??e, J. A Portable Centrifugal Analyser for Liver Function Screening. Biosens. Bioelectron. 2014, 56, 352-358.

(42) Czilwik, G.; Messinger, T.; Strohmeier, O.; Wadle, S.; von Stetten, F.; Paust, N.; Roth, G.; Zengerle, R.; Saarinen, P.; Niittymäki, J.; et al. Rapid and Fully Automated Bacterial Pathogen Detection on a Centrifugal-Microfluidic LabDisk Using Highly Sensitive Nested PCR with Integrated Sample Preparation. Lab Chip 2015, 15 (18), 3749-3759.

(43) Michael, I. J.; Kim, T. H.; Sunkara, V.; Cho, Y. K. Challenges and Opportunities of Centrifugal Microfluidics for Extreme Point-of-Care Testing. Micromachines 2016, 7 (2), 1-14.

(44) Maguire, I.; Fitzgerald, J.; McPartlin, D.; Heery, B.; Murphy, C.; Nwankire, C.; O'Kennedy, R.; Ducree, J.; Regan, F. A Centrifugal Microfluidic-Based Approach for Multi-Toxin Detection for Real-Time Marine Water-Quality Monitoring. In OCEANS 2017 Aberdeen; IEEE, 2017; pp 1-8.

(45) Czugala, M.; Maher, D.; Collins, F.; Burger, R.; Hopfgartner, F.; Yang, Y.; Zhaou, J.; Ducrée, J.; Smeaton, A.; Fraser, K. J.; et al. CMAS: Fully Integrated Portable Centrifugal Microfluidic Analysis System for on-Site Colorimetric Analysis. RSC Adv. 2013, 3 (36), 15928.

(46) Nwankire, C. E.; Donohoe, G. G.; Zhang, X.; Siegrist, J.; Somers, M.; Kurzbuch, D.; Monaghan, R.; Kitsara, M.; Burger, R.; Hearty, S.; et al. At-Line Bioprocess Monitoring by Immunoassay with Rotationally Controlled Serial Siphoning and Integrated Supercritical Angle Fluorescence Optics. Anal. Chim. Acta 2013, $781,54-62$.

(47) Ding, Z.; Zhang, D.; Wang, G.; Tang, M.; Dong, Y.; Zhang, Y.; Ho, H.; Zhang, X. An In-Line Spectrophotometer on a Centrifugal Microfluidic Platform for Real-Time Protein Determination and Calibration. Lab Chip 2016, 16 (18), 3604-3614.

(48) Delgado, S. M. T.; Sandoval, F. S.; Korvink, J. G.; Mager, D. A Universal and Stand-Alone Datalogger for Lab-on-a-Disc Applications. 2016 IEEE Wirel. Power Transf. Conf. WPTC 2016 2016, No. 3, 2-5.

(49) Delgado, S. M. T.; Kinahan, D. J.; Sandoval, F. S.; Julius, L. A. N.; Kilcawley, N. A.; Ducrée, J.; Mager, D. Fully Automated Chemiluminescence Detection Using an Electrified-Lab-on-a-Disc (ELoaD) Platform. Lab Chip 2016, 16 (20), 4002-4011.

(50) Torres Delgado, S. M.; Kinahan, D. J.; Nirupa Julius, L. A.; Mallette, A.; Ardila, D. S.; Mishra, R.; Miyazaki, C. M.; Korvink, J. G.; Ducrée, J.; Mager, D. Wirelessly Powered and Remotely Controlled Valve-Array for Highly Multiplexed Analytical Assay Automation on a Centrifugal Microfluidic Platform. Biosens. Bioelectron. 2018, 109 (February), 214-223.

(51) Torres Delgado, S. M.; Korvink, J. G.; Mager, D. The ELoaD Platform Endows Centrifugal Microfluidics with On-Disc Power and Communication. Biosens. Bioelectron. 2018, 117, 464 473.

(52) Bauer, M.; Bartoli, J.; Martinez-Chapa, S.; Madou, M. Wireless Electrochemical Detection on a Microfluidic Compact Disc
(CD) and Evaluation of Redox-Amplification during Flow. Micromachines 2019, 10 (1), 31.

(53) L. Amato; Sanger, K.; Tehrani, S. E.; Burger, R.; Caviglia, C.; Z.Andreasen, S.; Heiskanen, A.; Emnéus, J.; A. Boisen, A. B. A Lab-on-a-Disc Platform for Trapping of Cells, Monitoring of Cell Behaviour and Evaluation of Redox Metabolism. Proc. MicroTAS2015.Chemical Biol. Microsystems Soc. 2015, 1299-1302.

(54) Andreasen, S. Z.; Sanger, K.; Jendresen, C. B.; Nielsen, A. T.; Emnéus, J.; Boisen, A.; Zór, K. Extraction, Enrichment, and in Situ Electrochemical Detection on Lab-on-a-Disc: Monitoring the Production of a Bacterial Secondary Metabolite. ACS Sensors 2018, acssensors. 8b01277.

(55) Nielsen, L. H.; Keller, S. S.; Gordon, K. C.; Boisen, A.; Rades, T.; Müllertz, A. Spatial Confinement Can Lead to Increased Stability of Amorphous Indomethacin. Eur. J. Pharm. Biopharm. 2012, 81, 418-425.

(56) Nielsen, L. H.; Melero, A.; Keller, S. S.; Jacobsen, J.; Garrigues, T.; Rades, T.; Müllertz, A.; Boisen, A. Polymeric Microcontainers Improve Oral Bioavailability of Furosemide. Int. J. Pharm. 2016, 504, 98-109.

(57) Osteryoung, J. G.; Osteryoung, R. A. Square Wave Voltammetry. Anal. Chem. 1985, 57 (1), 101-110.

(58) Hsu, P. F.; Ciou, W. L.; Chen, P. Y. Voltammetric Study of Polyviologen and the Application of Polyviologen-Modified Glassy Carbon Electrode in Amperometric Detection of Vitamin C. $J$. Appl. Electrochem. 2008, 38 (9), 1285-1292.

(59) Pisoschi, A. M.; Pop, A.; Serban, A. I.; Fafaneata, C. Electrochemical Methods for Ascorbic Acid Determination. Electrochim. Acta 2014, 121, 443-460.

(60) Adhikari, B.-R.; Govindhan, M. Sensitive Detection of Acetaminophen with Graphene-Based Electrochemical Sensor. Electrochim. Acta 2015, 162, 198-204.

(61) Shiroma, L. Y.; Santhiago, M.; Gobbi, A. L.; Kubota, L. T. Separation and Electrochemical Detection of Paracetamol and 4Aminophenol in a Paper-Based Microfluidic Device. Anal. Chim. Acta 2012, 725, 44-50.

(62) Manjunatha, R.; Nagaraju, D. H.; Suresh, G. S.; Melo, J. S.; D'Souza, S. F.; Venkatesha, T. V. Electrochemical Detection of Acetaminophen on the Functionalized MWCNTs Modified Electrode Using Layer-by-Layer Technique. Electrochim. Acta 2011, 56 (19), 6619-6627.

(63) Alam, A. U.; Qin, Y.; Howlader, M. M. R.; Hu, N.-X.; Deen, M. J. Electrochemical Sensing of Acetaminophen Using MultiWalled Carbon Nanotube and $\beta$-Cyclodextrin. Sensors Actuators $B$ Chem. 2018, 254, 896-909.

(64) Teng, Y.; Fan, L.; Dai, Y.; Zhong, M.; Lu, X.; Kan, X. Electrochemical Sensor for Paracetamol Recognition and Detection Based on Catalytic and Imprinted Composite Film. Biosens. Bioelectron. 2015, 71, 137-142.

(65) Bergström, C. A. S.; Holm, R.; Jørgensen, S. A.; Andersson, S. B. E.; Artursson, P.; Beato, S.; Borde, A.; Box, K.; Brewster, M.; Dressman, J.; et al. Early Pharmaceutical Profiling to Predict Oral Drug Absorption: Current Status and Unmet Needs. Eur. J. Pharm. Sci. 2014, 57, 173-199.

(66) Azarmi, S.; Roa, W.; Löbenberg, R. Current Perspectives in Dissolution Testing of Conventional and Novel Dosage Forms. Int. J. Pharm. 2007, 328, 12-21.

(67) Nielsen, L. H.; Keller, S. S.; Boisen, A. Microfabricated Devices for Oral Drug Delivery. Lab on a Chip. 2018, pp 2348-2358.

(68) Fox, C. B.; Kim, J.; Le, L. V.; Nemeth, C. L.; Chirra, H. D.; Desai, T. A. Micro/Nanofabricated Platforms for Oral Drug Delivery. J. Control. Release 2015, 219, 431-444.

(69) Mazzoni, C.; Tentor, F.; Strindberg, S. A.; Nielsen, L. H.; Keller, S. S.; Alstrøm, T. S.; Gundlach, C.; Müllertz, A.; Marizza, P.; Boisen, A. From Concept to in Vivo Testing: Microcontainers for Oral Drug Delivery. J. Control. Release 2017, 268 (October), 343351.

(70) von Halling Laier, C.; Gibson, B.; Moreno, J. A. S.; Rades, T.; Hook, S.; Nielsen, L. H.; Boisen, A. Microcontainers for Protection of Oral Vaccines, in Vitro and in Vivo Evaluation. $J$. Control. Release 2019, 294, 91-101. 
(71) Abramson, A.; Caffarel-Salvador, E.; Khang, M.; Dellal, D.; Silverstein, D.; Gao, Y.; Frederiksen, M. R.; Vegge, A.; Hubálek, F.; Water, J. J.; et al. An Ingestible Self-Orienting System for Oral Delivery of Macromolecules. Science 2019, 363 (6427), 611-615.

(72) Siewert, M.; Dressman, J.; Brown, C. K.; Shah, V. P.; Aiache, J.-M.; Aoyagi, N.; Bashaw, D.; Brown, C.; Brown, W.; Burgess, D.; et al. FIP/AAPS Guidelines to Dissolution/in Vitro Release Testing of Novel/Special Dosage Forms. AAPS PharmSciTech 2003, 4 (1), 43-52. 